\title{
Understanding blood oxygenation in a microfluidic meander double side membrane contactor
}

M. Malankowska, ${ }^{\mathrm{a}, \mathrm{b}}$ I. Julian, ${ }^{\mathrm{a}}$ I. Pellejero, ${ }^{\mathrm{a}, \mathrm{c}}$ H.S. Rho, ${ }^{\mathrm{b}}$ S. Schlautmann, ${ }^{\mathrm{b}}$ R.M. Tiggelaar, ${ }^{\mathrm{b}, \mathrm{d}}$ M.P. Pina, ${ }^{* a, e}$ H.J.G.E. Gardeniers, ${ }^{b}$ and R. Mallada* ${ }^{a, e}$

${ }^{a}$ Institute of Nanoscience of Aragon, Department of Chemical and Environmental Engineering, University of Zaragoza, Edif. I+D+i, Campus Río Ebro, C/ Mariano Esquillor, 50018 Zaragoza, Spain

${ }^{\mathrm{b}}$ Mesoscale Chemical Systems, MESA+ Institute for Nanotechnology, University of Twente, P.O. Box 217, 7500 AE Enschede, The Netherlands

'Institute for Advanced Materials, Public University of Navarra, Edif. Jerónimo de Ayanz, Campus Arrosadia, s/n, 31006 Pamplona-Iruña, Spain

${ }^{d}$ MESA+ NanoLab cleanroom, MESA+ Institute for Nanotechnology, University of Twente, P.O. Box 217, 117500 AE Enschede, The Netherlands

${ }^{\mathrm{e}}$ Networking Research Centre on Bioengineering, Biomaterials and Nanomedicine, CIBER-BBN, 28029 Madrid, Spain

\section{ABSTRACT}

Lung disease is one of the most important causes of high morbidity in preterm infants. In this work, we study a simple and easy to fabricate microfluidic device that demonstrates a great potential for blood oxygenation. A meander type architecture with double side vertical membrane arrangement has been selected as reference model to investigate the oxygenation process. The design criteria for the fabricated devices has been to maximize the oxygen saturation level while ensuring the physiological blood flow in order to avoid thrombus formation and channel blockage during operation. A mathematical model for the oxygen transfer has been developed and validated by the experimental study. The obtained results demonstrate that blood was successfully oxygenated up to approximately $98 \%$ of $\mathrm{O}_{2}$ saturation and that the oxygen transfer rate at $1 \mathrm{~mL} / \mathrm{min}$ blood flow rate was approximately 92 $\mathrm{mL} / \mathrm{min} \cdot \mathrm{m}^{2}$. Finally, a sensitivity analysis of the key parameters, i.e. size of the channel, oxygen concentration in the gas phase and oxygen permeation properties of the membrane, is carried out to discuss the performance limits and to settle the guidelines for future developments.

Keywords:

Blood oxygenation, microfluidic membrane contactor. 


\section{Introduction}

The urge of new technologies for blood oxygenation in lung assist devices appeared as a result of a high morbidity caused by pulmonary disorders. Lung transplantation is nowadays the only available clinical therapy for adults with the end-stage of chronic lung disease. However, the regular time that patients need to wait for the organ transplantation is 2 years, and approximately $10 \%$ of them are dying while waiting for the organ to be available. Moreover, preterm infants who are born younger than 32 weeks are at extremely high risk of suffering from severe respiratory problems as a result of smaller available surface area for gas exchange or due to the poor diffusion properties of their lung's membrane [1]. The lung transplant cannot be executed due to the fact that implanted organs in infants do not grow with them. Mechanical ventilation is a commonly used technique for delivering sufficient amount of oxygen; however, some serious complications may occur for small lung tissue which is under development. These factors drew the attention to the development of a new technology which will assist in blood oxygenation.

Along the last years, a biomimetic microfluidic technology has been developed and reported by several authors [1-6] and recently reviewed by J. Potkay [7-8] for the application of lung assist device. In these microchips blood flows through vascular microchannels which are physically separated from an oxygen stream by a gas permeable membrane. Oxygen permeates through the membrane and enters the blood first as dissolved oxygen in plasma and later becomes bonded to haemoglobin $(\mathrm{Hb})$, which implies that the mass transfer resistance is mainly located in the liquid phase for the vast majority of the oxygenation tests. When small blood channel diameters (lower than $30 \mu \mathrm{m}$ ) and thick membranes (thickness higher than $50 \mu \mathrm{m}$ ) are considered, the membrane resistance may be comparable to the offered by the liquid phase or even dominant. The possible benefits of such microfluidic chips include: 1) small surface area and priming volume which leads to a decrease of the device dimensions, 2 ) improved biocompatibility thanks to the blood chamber architecture that mimics the structure of a natural lung so cells and platelets experience pressures, shear stresses and branching angles similar to a human organ, 3 ) increased gas exchange capacity that enables the respiratory support for patients who are not only in rest [7].

Nowadays researchers are mastering the design and fabrication of lung assist devices in the form of a microfluidic chip, the so called microfluidic artificial lungs ( $\mu A L s$ ). Various 
materials and morphologies of membranes integrated in the microfluidic devices were examined by the group of Prof. Vacanti at the Centre of Regenerative Medicine, Massachusetts General Hospital, USA. Dense and porous polycarbonate (PC) and different silicone membranes were taken into account and the oxygen transfer rate obtained for all the membranes was similar even at various thicknesses $[2,3]$. Potkay et al. focused their efforts on the optimization of the liquid chamber dimensions, for very shallow blood channel depths, i.e. $20 \mu \mathrm{m}$ and $10 \mu \mathrm{m}$ [9]. Recently, flat two-dimensional $\mu$ ALs stacked in parallel with a capillary height of $30 \mu \mathrm{m}$ has been demonstrated as a trade-off to maximize oxygenation performance and reduce the number of layers that are needed for a clinically-relevant device [8]. The same group developed a new manufacturing approach for scaling up based on roll to roll polymer sheet processing [6]. In particular, a $\mu \mathrm{AL}$ with a four-layer structure (blood layer $10 \mu \mathrm{m}$ height /membrane $66 \mu \mathrm{m}$ thick/air layer/capping layer) was assembled by rolling a cylindrical substrate over the patterned PDMS substrate. The in vitro experiments were performed resulting in high gas exchange rates. Nevertheless, the authors concluded that scaling up the device could be challenging due to the fabrication limitations for large area devices.

It was noticed that the shallower the blood channels the shorter the pathway that oxygen has to pass to bind to $\mathrm{Hb}$ and thus the fastest the blood oxygenation. However, extremely elevated pressure drop and shear stress were observed on the liquid side which could lead to chamber collapse or channel blockage by red blood cells (RBCs) due to the non-homogenous blood flow, i.e. blood accumulation in certain zones of the structure. Consequently, thanks to the development of soft-lithography, a large variety of more complicated structures have been examined by different authors. Liquid chamber architectures with branching channels, imitating the natural lung, that obeyed bifurcation theory were designed by Kniazeva et al.[10, 11]. Especially, Hoganson et al. presented an outstanding liquid chamber design in terms of physiological blood flow. The proposed system possessed various channel depths along the entire structure, i.e. from $700 \mu \mathrm{m}$ to $100 \mu \mathrm{m}$, and branching architecture [12]. This procedure significantly decreased pressure drop and shear stress along the chamber. Selvaganapathy et al. fabricated interesting stainless steel reinforced composite silicone membranes to improve gas exchange performance. The composite membrane consisted of ultra-thin stainless-steel mesh embedded in PDMS that demonstrated high stability, low deformation under pressure and high gas exchange [13]. 
Essential points that need to be further studied are the optimization of liquid chamber geometries easy to fabricate and suitable for scaling up that keep cardiovascular parameters and blood specifications in desired range; and, the creation of the right balance between chip mechanical stability and good oxygenation performance. Crucial restrictions for the liquid side that need to be obeyed in order to keep the blood at physiological level include three main aspects: i) shear stress should not exceed the normal range in the human vascular system of 0.1 to $7 \mathrm{~N} / \mathrm{m}^{2}$ [12], ii) pressure drop, the arteriovenous pressure difference for neonates is in the range of 26.7 to 79.9 mbar [13] iii) the distribution of blood flow should be homogenous [14-15]. Assuming an extracorporeal bypass volume of $30 \mathrm{~mL} \cdot \mathrm{kg}^{-1} \cdot \mathrm{min}^{-1}$ (i.e. $10 \%$ of the output volume is circulating extra-corporeally), it was estimated that to increase the oxygen saturation in blood from $70 \%$ to $100 \%$, the oxygen transfer rate in a microdevice should be $1.9 \mathrm{~mL} \cdot \mathrm{kg}^{-1} \cdot \mathrm{min}^{-1}[1]$.

Unlike previously described $\mu A L s$, a meander type architecture with oxygen and blood channels in the same plane is herein investigated for the first time. The gas-liquid separating walls constitute a gas permeation membrane. Such geometrical conformation provides double side gas diffusion, i.e. duplicate the gas exchange area, thereby doubling gas exchange; which benefits the compactness of the system. Above all, the main advantage of the single layer, meandering structure is that it notably simplifies manufacturing process by removing the need to fabricate separate blood, membrane, and gas layers which decreases the probability of imperfection in bonding, membrane morphology or device structure.

In this work, a simple and easy to fabricate meander type microfluidic device for blood oxygenation is studied. First, the fluid dynamics of the conceptual microdevice are analysed and the physiological conditions are ensured. Next, the fabrication procedure for a meander type architecture with oxygen and blood channels in the same plane, where the separating walls constitute a permeation membrane will be described, followed by an outline of the experimental methodology. The oxygenation performance of the obtained microdevices is evaluated and compared to that predicted by a mathematical model. Finally, a sensitivity analysis for width of the microchannel, oxygen concentration in the gas phase and oxygen permeation properties of the membrane is carried out to identify the parameters that exert the strongest influence. A basic metrics comparison with previous published results and guidelines for the future development of an improved oxygenator structure for preterm infants are given. 


\section{Numerical and experimental methods}

\section{Design and computational fluid dynamics models}

In the proposed design (see Figure 1), the liquid chamber (red colour) is surrounded by gas channels (blue colour) from both sides and separated by a gaspermeable PDMS membrane. The entire PDMS structure is closed by a glass slide at the bottom. The total surface area for gas exchange is thus the lateral area of one meander unit multiplied by the number of units and the number of branches of the entire structure (see Figure 1 for the entire design). The PDMS wall between the gas channel and the liquid channel is the actual membrane thickness. Therefore, the gas-liquid contact area, i.e. the membrane surface, depends on the depth and the length of the channels. A larger channel depth is beneficial because it increases the gas-liquid contact area, which is favourable for the oxygen saturation level.

The presented configuration requires a manufacturing process that does not require a separate step for the fabrication of the membrane, which usually includes peeling off of a thin film from a support (e.g. a Si wafer), a technique commonly used in the microfabrication of membranes for artificial microfluidic oxygenators [7]. Instead, the entire structure is embedded in the same layer. Moreover, the oxygen enters the blood channel from both sides, giving double side diffusion (see the magnification in Figure 1) which increases blood oxygenation per unit of length. Considering that the oxygen comes from the sides of the channel instead of from the top of it, as it is commonly done, narrowing of the liquid channel will increase the $\mathrm{O}_{2}$ transfer rate and will decrease the actual dimensions of the chip because the same surface area will be loaded in a smaller chip footprint. On the other hand, it should be noted that the channels should not be made too narrow, to keep low the pressure drop and shear stress for a given flow rate. In this study the balance between these parameters has been taken into account in the selection of the key feature sizes.

Numerical modelling was used to drive the design of the artificial capillaries in the proposed meandering channel gas-liquid contactor, with an emphasis on homogenous liquid flow, low pressure drop and shear stress as well as high surface to volume ratio. The liquid flow distribution in the microchannels was numerically solved in 2D using $\mathrm{COMSOL}^{\circledR}$ Multiphysics 5.0 software. In order to describe the flow of blood along the designed microchannel, laminar flow physics were adapted for blood inside the liquid chamber geometry. The momentum conservation for laminar flow of 
incompressible fluids (Equation 1) was solved together with the mass conservation (Equation 2), using the Navier-Stokes equations:

$\rho(\mathbf{u} \cdot \nabla) \mathbf{u}=\nabla \cdot\left[-p \mathbf{I}+\mu\left(\nabla \mathbf{u}+(\nabla \mathbf{u})^{T}\right)-\frac{2}{3} \mu(\nabla \cdot \mathbf{u}) \mathbf{I}\right]+\mathbf{F}$

$\nabla \cdot(\rho \mathbf{u})=0$

Where, $\rho$ is the blood density, $u$ stands for the flow velocity vector field, $p$ is the pressure, $\mu$ is the blood viscosity and superscript $T$ is transposed of a matrix. In Equation 1 , the terms on the left side are acceleration forces and on the right side pressure gradient and viscous forces. Following assumptions have been made: no slip condition on the walls of the liquid chamber geometry; $u=0$, no back-flow permitted, the flow direction was defined as normal to the chamber inlet and outlet, and the outlet pressure was set at $1 \mathrm{~atm}$. The set of governing equations was solved using a finite element method. The convergence criterion was based on the residual error in the momentum equation, which was set to $10^{-3}$.

A variety of meandering architectures were examined in order to find the optimum one in terms of the criteria previously mentioned. The chosen structure has a liquid channel width of $400 \mu \mathrm{m}$, gas channel width of $100 \mu \mathrm{m}$ and the spacing in between (the membrane thickness) of $120 \mu \mathrm{m}$. The depth of the entire structure is equal to $100 \mu \mathrm{m}$. It is made of 19 meandering units and 9 branches loaded on a surface of $35.04 \mathrm{~cm}^{2}$ of total chip footprint. Table 1 shows the main parameters of the proposed meander type chip.

The final model structure consisted of more than 40000 triangular elements defining a structured mesh with an edge length in the range $0.04-0.005 \mathrm{~cm}$. Figure 2 shows the results of the fluid dynamic modelling of the liquid chamber for (A) liquid flow velocity, (B) pressure drop and (C) shear stress, respectively, at $1 \mathrm{~mL} / \mathrm{min}$ blood flow rate. It is visible that the liquid flow profile is homogenous and that the liquid enters all the branches with the same velocity. This ensures that in the proposed structure there will not be a risk of dead zones or mass accumulation. The mathematically calculated $\Delta \mathrm{P}$ and shear stress for $1 \mathrm{~mL} / \mathrm{min}$ blood flow rate is equal to 16.9 mbar and $3.42 \mathrm{~N} / \mathrm{m}^{2}$, respectively indicating that there will not be a risk of thrombus formation inside the liquid channels. The experimental measurements of pressure drop in the liquid chamber agree well with the calculated values, i.e. 18.4 mbar vs. 16.9 mbar (see Figure S1 in the Supplementary Material for more details). 
Moreover, Mockros and Cook [16]: analysed the shear-induced and material induced blood trauma factor, $T_{F, S}$ and $T_{F, M}$, respectively from equation (3) and (4)

$$
\begin{aligned}
& T_{F, S}=\tau_{\text {avg }}^{2}-\frac{900}{t_{R}}-225 \\
& T_{F, M}=\tau_{a v g}^{2}+\frac{2}{t_{R}}-16
\end{aligned}
$$

Where, $\tau_{\text {avg }}$ is the average shear stress that the blood is experiencing and $t_{R}$ is the residence time of blood in the device. The $T_{F, S}$ should be lower than zero and $T_{F, M}$ should be greater than zero to avoid blood trauma. In the case of our oxygenator device the $T_{F, S}$ is equal to -250.9 and -473.4 for 0.1 and $1 \mathrm{~mL} / \mathrm{min}$ blood flow rate, respectively. These values show that there was no shear-induced platelet activation. On the other hand, $T_{F, M}$ is equal to -15.8 and -3.73 for 0.1 and $1 \mathrm{~mL} / \mathrm{min}$, respectively. These values indicate that the material-induced blood trauma due to stagnation was present. Experimentally, we did not record any accumulation of activated coagulation factors in the structure, mainly due to the use of EDTA as anticoagulant, as described in the oxygenation set-up section.

\section{Oxygen mass balance}

The mass balance and transport equation for oxygen species in blood was developed from a standard convection-diffusion mass transfer expression [11, 17-18]. When blood enters the microchannel, the partial pressure of dissolved oxygen is low (see Figure 3B). As the blood flows along the channel, oxygen diffuses out of the gas side of the chip, across the membrane and into the blood, dissolving in blood plasma and then diffusing to and into red blood cells and binding to haemoglobin.

The oxygen pressure on the gas side of the device has been considered constant due to: i) the resistance to diffusion on the gas side of the device is negligible compared to that of the membrane and blood, and ii) its supply is higher than its gas exchange rate. These assumptions are also made in the simple closed-form model developed by Potkay [19] for oxygen diffusion; who considered, unlike in this work, that the partial pressure of gases in blood does not vary along the width and height of the liquid channel.

The partial differential equation that governs the oxygen transport in the blood under steady state operation can be expressed as follows [15]:

$$
\mathrm{u} \cdot \nabla P_{O 2}=D_{e f f} \cdot \nabla^{2} P_{O 2}
$$


Where, $D_{\text {eff }}$ is the effective diffusivity of oxygen in blood which incorporates the effects of oxygen uptake by haemoglobin introduced first by Mockros and Leonard [17]. Such effective diffusivity is calculated from Equations 6 to 8:

$$
D_{e f f}=\frac{D_{b}}{1+\lambda(P)}
$$

Where, $D_{b}$ is the $\mathrm{O}_{2}$ diffusion coefficient in plasma and $\lambda(P)$ is the mathematical term developed to account $\mathrm{O}_{2}$ bound to $\mathrm{Hb}$. It is expressed as a function of oxygen concentration in haemoglobin, denoted as $[\mathrm{Hb}]$, according to Equation 7, being $\alpha$ the oxygen solubility in plasma:

$$
\lambda(P)=\frac{1.34[\mathrm{Hb}] \cdot \mathrm{S}^{\prime}{ }_{\mathrm{O}}}{\alpha}
$$

And $\mathrm{S}^{\prime}{ }_{\mathrm{O} 2}$ is:

$$
S^{\prime}{ }_{O 2}=\frac{n\left(P_{50}\right)^{n} \cdot P_{O 2}^{n-1}}{\left(P_{50}^{n}+P_{O 2}^{n}\right)^{2}}
$$

and can be derived from the oxygen-binding equilibrium of $\mathrm{Hb}$ known as the Hill's equation $[17,20]$ :

$$
\mathrm{S}_{\mathrm{O} 2}=\frac{\left(\frac{\mathrm{P}_{02}}{\mathrm{P}_{50}}\right)^{\mathrm{n}}}{1+\left(\frac{\mathrm{P}_{02}}{\mathrm{P}_{50}}\right)^{\mathrm{n}}}
$$

where: $S_{O 2}$ is the fractional oxygen saturation, $n$ is the number of binding sites of haemoglobin (called the Hill coefficient), and $P_{50}$ is the partial pressure of oxygen when blood is $50 \%$ saturated. The parameter $\mathrm{n}$ of the Hill equation is taken to be constant for a particular blood specie, being $n=2.85$ for bovine blood. This number was also corroborated by Zhang et al. [20] fitting the experimental data of saturation to the Hill curve obtaining a value of $n=2.84$ and $P_{50}=38.7$ mbar. The parameter $P_{50}$ [mbar] depends upon $\mathrm{pH}$ and temperature, $\mathrm{T}$, according to Equation 10, for bovine blood [17]:

$$
P_{50}=38.7 * 10^{(-0.41)(7.4-p H)} * 10^{(-0.024)(37-T)}
$$

Rearranging the above equations, the effective diffusivity is expressed as follows:

$$
D_{\text {eff }}=\frac{D_{b}}{1+\frac{1.34[H b] \cdot n\left(P_{50}\right)^{n \cdot\left(P_{O 2}\right)^{n-1}}}{\alpha\left(P_{50}^{n}+P_{O 2}^{n}\right)^{2}}}
$$

The coupling between the oxygen mass balance in the plasma and the membrane surface is obtained as a boundary condition in the liquid's mass balance. 
This condition sets the flux of oxygen at the boundary equal to the permeation rate through the PDMS membrane, $\mathrm{J}_{\mathrm{O} 2}$, and is presented below [21]:

$$
J_{O 2}=D_{m} \cdot \alpha_{m} \cdot\left(P_{G, O 2}-P_{O 2, w a l l}\right) \cdot \frac{1}{t_{m}}
$$

where $D_{m}$ is the diffusion coefficient for oxygen in the PDMS membrane, $\alpha_{m}$ is the solubility of oxygen in the PDMS membrane, $t_{m}$ is the thickness of the membrane, $\mathrm{P}_{\mathrm{O} \text {, wall }}$ is the partial pressure of dissolved oxygen at the thin film wall, $\mathrm{P}_{\mathrm{G}, \mathrm{O} 2}$ is the partial pressure of oxygen in the gas side. The product of $D_{m}$ and $\alpha_{m}$ corresponds to the oxygen permeability, denoted as Perm, of the PDMS membrane. Table 2 shows the main constant parameters which are used in the calculations carried out in this work to evaluate the experimental and simulated oxygenation performance.

\section{Microfabrication and Testing Microdevice fabrication}

The microfluidic device used in this work was made of Polydimethylsiloxane (PDMS; Sylgard 184 Dow Corning, Midland, MI) which was chosen because of its optical transparency, biocompatibility and high $\mathrm{O}_{2}$ and $\mathrm{CO}_{2}$ permeability (see Table 2) $[22,26]$. Furthermore, its highly elastic properties enable that it can be easily released from moulds and conform to surfaces.

The meander architecture was fabricated using a procedure reported previously by several authors [2, 11, 23-24]. Briefly, the masters were prepared by standard photolithography to create a pattern in SU-8 photoresist (SU-8 50 DE MicroChem) deposited on a flat silicon substrate. PDMS pre-polymer and curing agent were thoroughly mixed in a ratio $10: 1$ and placed in a desiccator for degassing. PDMS was poured on the masters and placed in an oven for $45 \mathrm{~min}$ at $80^{\circ} \mathrm{C}$. The mould was peeled off from the silicon wafer, cut to the required size and punched for inlets and outlets by a round punch (TiN Coated Round Punch, Syneo). The fabricated chamber was immersed in isopropanol (Sigma Aldrich) and placed in an ultrasound bath for approximately 2 minutes in order to remove any possible dust that could be attached to the inside of the channels, or PDMS debris inside the punched holes. The fabricated PDMS platform was placed inside an oxygen plasma chamber (Diener electronic, Plasma-surface-technology) operating at 0.4 mbar, $120 \mathrm{~W}$ and $50 \%$ of $\mathrm{O}_{2}$ during $50 \mathrm{sec}$, in order to activate the surface, which enabled connecting the PDMS platform to glass [25]. The chamber and the glass slide were connected and placed in an oven at $85^{\circ} \mathrm{C}$ for 
1 hour. Next, metallic pins in the form of bridges were inserted at the gas inlets of each branch in order to supply gas to each liquid unit and arm. The volume of the metallic pins for each microdevice is circa $17 \mu \mathrm{L}$.

\section{Microfluidic device characteristics}

The liquid chamber architecture enabled uniform blood flow through the meandering liquid microchannels while supplying pure $\mathrm{O}_{2}$ permeating through a PDMS membrane from both lateral sides of the chamber. The gas or liquid was introduced to the chip by Tygon microbore tubing $\left(0.020^{\prime \prime} \times 0.060 "\right.$ OD, Cole-Parmer, The Netherlands) and precision stainless steel dispense tip (0.010" ID, 0.020 OD, $45^{\circ}$ bend, Nordson, The Netherlands). The bridges which were connecting the gas channels were made of the same precision stainless steel dispense tips (see Figure 4C). Figure 4 gives SEM images (A, B) and a photograph of a meandering microfluidic device with coloured liquid (red colour) and gas (green colour) channels for better visualisation (Figure $\mathrm{C}$ and Figure $4 \mathrm{C1}$ ). The image indicates that the filling of the liquid channels was homogenous and well distributed without dead volumes. It is also important to note that in this architectural conformation there was no risk of membrane deflection or detachment since the membrane is embedded and structurally integrated in the chamber. The fabricated devices were tested under the experimental conditions described above. No leak or chamber collapse was observed. The device was able to operate for at least 8 hours at a blood flow rate of $1 \mathrm{~mL} / \mathrm{min}$ without channel collapse or blockage. Three identical meander type microfluidic devices were fabricated and tested. For all of them, the thickness of the PDMS mould for the mixed PDMS compartment was approximately $0.8-1 \mathrm{~cm}$ and the chip footprint was equal to $35 \mathrm{~cm}^{2}$, making it a very compact system.

\section{Oxygenation set-up}

The device performance was tested by measuring the blood oxygenation in the experimental system presented in Figure 5. All the oxygenation experiments were carried out with sheep blood obtained from Faculty of Veterinary at University of Zaragoza. The blood samples were collected and transferred into $10 \mathrm{~mL}$ plastic tubes (Becton Dickinson B.V., Spain) with Ethylenediaminetetraacetic acid (EDTA) as anticoagulant in a concentration of $1.5 \mathrm{mg} / \mathrm{mL}$. The haemoglobin concentration of each batch was measured by gasometry (Vet abc, Animal Blood Counter). Blood was stored under refrigeration at $4^{\circ} \mathrm{C}$ during a maximum period before essays of 24 hours.

Obtained blood was a venous blood with an oxygenation of approximately $98 \%$. Therefore, it was necessary to deoxygenate it prior to the oxygenation experiment. 
First, $50 \mathrm{~mL}$ of blood was transferred into a glass bottle and placed on a stirring plate inside a climatic chamber in order to maintain a temperature of $37^{\circ} \mathrm{C}$. A mixture of air and nitrogen with $7.8 \%$ of $\mathrm{O}_{2}$ was bubbled directly to the blood for approximately 1 hour in order to decrease the $\mathrm{O}_{2}$ blood saturation down to approximately $70 \%$. Afterwards, the deoxygenated blood was transferred into a $50 \mathrm{~mL}$ syringe (Becton Dickinson B.V., Spain) and placed in a syringe pump (Harvard Apparatus, Spain). The experiments were performed at blood flow rates ranging from 0.1 to $1 \mathrm{~mL} \cdot \mathrm{min}^{-1}$. A pressure transducer (Panasonic, DP2-41E) was placed right after the syringe pump to evaluate the pressure drop across the entire system, taking into account the device itself, piping and metallic pins. Next, the gas chamber was purged with pure oxygen while deoxygenated blood entered the microdevice from the liquid chamber side. The initial outlet blood stream was discarded by pumping it to the waste reservoir to ensure steady state conditions in the analysed sample (after approximately 2 minutes of blood flowing through the system, depending on the blood flow rate). The oxygenated blood was collected in a glass bottle hermetically sealed in which a pH electrode (Hamilton, Slimtrode 238150, Switzerland) and a dissolved oxygen electrode, type oximeter (ThermoFisher Scientific, Orion Star A223), were immersed. Before each set of experiments, a control sample measurement was performed by passing the blood throughout the experimental system without oxygenating it (i.e. $\mathrm{O}_{2}$ mass flow controller and gas outlet closed), in order to ensure that no leaks are present in the system, and that there is no blood oxygenation by the oxygen stored in the head space of the blood collecting bottle.

Three repetitions, one for each identical meander device, were performed at distinctive blood flow rates. The concentration of haemoglobin slightly differed from sample to sample. Therefore, for each experiment, the $\mathrm{Hb}$ concentration was measured by gasometry. The main blood inlet parameters for each oxygenation experiment are shown in Table 3 (see Table S1 in the Supplementary Material for the output blood values and oxygen transfer rates estimated for the three identical devices).

The $\mathrm{O}_{2}$ transfer rates, $\mathrm{O}_{2 \text { transf }}\left(\mathrm{mol} \cdot \mathrm{m}^{-2} \cdot \mathrm{s}^{-1}\right)$, through the membrane was calculated according to the following Equation 13:

$$
O_{2 \text { transf }}=\frac{\alpha \cdot \Delta P_{O 2}+H b s \cdot \Delta S_{O 2} \cdot[H b]}{S A} \cdot Q
$$

Where: $\alpha$ is the solubility coefficient of $\mathrm{O}_{2}$ in blood plasma (see Table 2 ), $\Delta \mathrm{P}_{02}$ [mbar] is the difference between the outlet and inlet values of partial pressure that 
corresponds to the dissolved oxygen measured. Thus, the term $\alpha \cdot \Delta P_{O 2}$ corresponds to the concentration of dissolved oxygen in plasma [1]. $\Delta \mathrm{S}_{\mathrm{O} 2}[-]$ is the increment in oxygen saturation in blood, $\mathrm{Hbs}$ is the $\mathrm{O}_{2}$ binding capacity of haemoglobin (see Table 2), [Hb] is the haemoglobin concentration in blood. The term $\mathrm{Hbs} \cdot \Delta \mathrm{S}_{\mathrm{O} 2} \cdot[\mathrm{Hb}]$ corresponds to the concentration of oxygen in blood that is bound to haemoglobin [1]. $Q$ is the blood flow rate and SA is the gas exchange surface area (see Supplementary Material for calculation details).

\section{Results and Discussion}

In Figure 6 we show the simulated oxygen concentration profiles along the meander type geometry for two liquid flow rates: A) $0.1 \mathrm{~mL} / \mathrm{min}(\operatorname{Re}=0.06)$ and B) 1 $\mathrm{mL} / \mathrm{min}(\mathrm{Re}=0.6)$ with their respective magnifications. As was expected, higher values of oxygen concentration are obtained at lower blood flow rates. Moreover, it can be observed that the highest values of the dissolved oxygen concentration are localized near the membrane wall. Figure 7 illustrates how experimental and simulated results on the total $\mathrm{O}_{2}$ transfer rate compare. The experimental and theoretical values are in very good agreement. The highest relative error of the oxygen transfer rate between experiment and model is present in the case of the highest blood flow rate, i.e. 1 $\mathrm{mL} / \mathrm{min}$ and is approximately $15 \%$.

Figure 8 shows the oxygen transfer rate at different blood flow rates in comparison to results of the leading research groups. The oxygenation obtained by Potkay et al. [9] results from the shallow channel depth of the liquid chamber, i.e. 10 $\mu \mathrm{m}$ or $20 \mu \mathrm{m}$ which suffered from a high pressure drop on the liquid side, $253 \mathrm{mbar}$ and 160 mbar, respectively. The $\mathrm{O}_{2}$ transfer rate achieved by Kniazeva et al. [10] with a branching architecture, equal to $223 \mathrm{~mL} / \mathrm{min} \cdot \mathrm{m}^{2}$ outperforms our results of 92 $\mathrm{mL} / \mathrm{min} \cdot \mathrm{m}^{2}$. This could be expected considering that the main transfer limitations occur on the liquid side and the channel depth in that case was $50 \mu \mathrm{m}$ compared to a diffusion distance in our channels of $400 \mu \mathrm{m}$ surrounded by a membrane on both sides. This means that in the meander device design we have a 4 times higher diffusion distance on the liquid side, compared to the branching architecture device, however the oxygen transfer rate is only 2.8 times lower. These results show that the simple meander design, with double side membrane, could be improved by narrowing the channels to achieve higher oxygenation. Using the validated model, we have pursued a sensitivity analysis to optimize the parameters in the meander design. 


\section{Sensitivity analysis of key parameters on oxygenation performance}

The effect of the following parameters: 1 ) oxygen concentration from the source gas, 2) membrane thickness, and 3) liquid channel width, on the overall performance of the fabricated microdevices was studied. The target of the parameter sensitivity study was to quantify the impact of a relative change of the considered parameters on the overall $\mathrm{O}_{2}$ transfer rate.

Figure 9A shows the effect of the oxygen concentration in the source gas on the blood oxygenation, keeping constant the PDMS membrane thickness (120 $\mu \mathrm{m})$ and channel width $(400 \mu \mathrm{m})$. Three oxygen concentrations were simulated: $100 \%, 60 \%$ and $21 \%$ of $\mathrm{O}_{2}$ entering the system from the gas side. As was expected, the highest $\Delta \mathrm{S}_{\mathrm{O} 2}$ and fastest $\mathrm{O}_{2}$ transfer is observed in case of pure oxygen, due to the highest driving force for permeation. This effect is more important in the case of higher flow, where an increase from $21 \%$ to pure oxygen multiplies the $\mathrm{O}_{2}$ transfer rate by nearly $100 \%$. Thus, it would be advisable to use pure oxygen to boost the oxygenation process. Next, the influence of the membrane thickness on the final performance of the chip is illustrated in Figure 9B, keeping constant the channel width $(400 \mu \mathrm{m})$ and using pure oxygen in the gas phase. The highest oxygenation was obtained in case of implementing the thinnest membrane due to the minimized resistance to gas diffusion through PDMS and the higher $\mathrm{P}_{02 \text {,wall }}$ values (partial pressure of oxygen at the membrane wall in contact with blood). This effect is more pronounced in the case of shorter residence time when not only the mass transfer limitations in the liquid phase occur but also there is a mass transfer resistance in the membrane. The computer simulation presented in Figure $9 \mathrm{C}$ shows the modification of the oxygen transfer rate and $S_{02}$ for $120 \mu m$ PDMS membrane and pure oxygen as a function of channel width, keeping the cross section of the channels constant, i.e. the same total volume of the liquid chamber to maintain the residence time constant for a given flow rate. Four channel widths were simulated: 400 $\mu \mathrm{m}, 300 \mu \mathrm{m}, 200 \mu \mathrm{m}$, and $100 \mu \mathrm{m}$. As it was expected, the thinner the channel the higher $\mathrm{O}_{2}$ transfer rate due to the shorter diffusion distance to bind to $\mathrm{Hb}$.

According to the simulated results, a weighted average factor was calculated assuming linear dependence to illustrate the impact of the different key parameters (expressed in dimensionless form) on the oxygen saturation values i.e. $\Delta \mathrm{S}_{\mathrm{O} 2}$, also expressed in dimensionless form. The calculation of such weight averaged sensitivity for oxygen concentration in the source gas is shown below: 


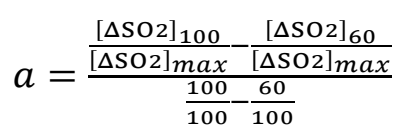

Where: $\left[\Delta \mathrm{S}_{\mathrm{O} 2}\right]_{100}$ and $\left[\Delta \mathrm{S}_{\mathrm{O}_{2}}\right]_{60}$ are mathematically oxygen saturation values obtained for a standard blood flow rate equal to $0.5 \mathrm{~mL} / \mathrm{min}$ at the $100 \% \mathrm{O}_{2}$ and $60 \%$ $\mathrm{O}_{2}$ in the source gas, respectively; and $\left[\Delta \mathrm{S}_{\mathrm{O}_{2}}\right]_{\max }$ corresponds to $100 \%$ oxygen saturation level at the outlet. The same calculation was repeated for membrane thickness and blood channel width variables. Thus, the estimated weight averaged sensitivity values are: $0.5,0.25$ and 0.1 for inlet oxygen concentration, membrane thickness and liquid channel width respectively.

The parametric sensitivity analysis showed that the factor with the highest impact on the blood oxygenation in the fabricated microfluidic meander device is the concentration of the supplied oxygen in the gas side due to the higher driving force. On the other hand, when pure oxygen is supplied to the gas chamber, the influence of membrane thickness over the oxygenation process is 1.5 fold higher than the effect exerted by the channel width.

Microfluidic devices for blood oxygenation represent an opportunity for decreasing priming volume, which is especially relevant in the case of neonates. Figure 10 illustrates how the total liquid chamber volume of the meander microdevice changes as a function of membrane thickness and blood channel width, when using pure oxygen, to guarantee $95 \%$ of blood oxygenation at the outlet at $0.1 \mathrm{~mL} / \mathrm{min}$ blood flow rate. In this parametric study, the blood saturation at the oxygenator inlet, the blood flow rate and channels depth were established, being $80 \%, 0.1 \mathrm{~mL} / \mathrm{min}$ and $100 \mu \mathrm{m}$, respectively. A total of 30 simulations were performed where five different channel widths were examined, i.e. in the range of 100-400 $\mu \mathrm{m}$, and six membrane thicknesses, i.e. in the range of $30-120 \mu \mathrm{m}$ (see Table S2 in the Supplementary Material for details of each simulation). Figure 10 shows, thus, the effect of miniaturization on blood oxygenation in the meander designed chip. Considering the low limit for arteriovenous pressure drop in neonates is 27 mbar [13], we have set this value as the maximum pressure drop in the microdevice. To minimize liquid chamber volume for a given gas exchange and blood flow rate, both parameters, membrane thickness and channel width, should be minimized as much as is practically possible. The reduction of the 
membrane thickness and liquid channel width to the set values from the sensitivity analysis, i.e. $100 \mu \mathrm{m}$, should be done in such a way that the current easy-of-fabrication by PDMS-casting \& release procedure should not be compromised. Fabrication of a thinner membrane $(50 \mu \mathrm{m})$ within the $100 \mu \mathrm{m}$ high channels will further improve the performance of the oxygenation device. However, various aspects have to be considered upon realization and operation of devices. First of all, it might be necessary to optimize the plasma bonding parameters [25] to reduce/minimize the risk for membrane delamination and thus to obtain a guaranteed membrane integrity in terms of engineering. Moreover, lateral membrane deflection can be prevented by balancing the liquid and gas flow rates, respectively. By means of modelling, it can be determined how much oxygen pressure (thus flow rate) should be applied to the gas channel to: i) counteract the pressure in the blood channel as induced by the blood flow; and, ii) to avoid the risk of gas bubbles formation in blood (due to pressure-driven convection of gas through the membrane). This is not a trivial task due to the fact that the pressure at the blood side might vary over time as a consequence of pumping or physiological reasons.

We envision that higher blood volumes can be handled by employing a larger number of the microfluidic devices presented here, arranging them in parallel, but keeping the functional dimensions of the microchannels and membrane configuration the same. The main issue in parallel arrangement of microfluidic networks is in the equal distribution of flows over the different elements. Recent work on 3D printed microchannel networks for 2D spatial separations may provide a route to cope with this problem [27].

Considering that rated blood flow, defined as the flow rate at which blood with an inlet $\mathrm{SO}_{2}$ of $70 \%$ is raised to $95 \%$ by the device, which is the parameter commonly adopted for devices inter-comparison; we have performed an additional simulation with the optimized microdevice to increase the oxygen saturation level by $25 \%$ at 0.1 $\mathrm{mL} / \mathrm{min}$ blood flow rate ensuring low pressure drop. Thus, $21.4 \mu \mathrm{L}$. $38.4 \mu \mathrm{L}, 4.1 \mathrm{~cm}^{2}$ and $8.2 \mathrm{~cm}^{2}$ are the estimated liquid chamber volume, priming volume (including fluidic connections and flow distributors), gas exchange surface area and total blood contacting area values, respectively for the optimized single unit with $100 \mu \mathrm{m}$ channel width and $100 \mu \mathrm{m}$ membrane thick (see last row of Table S2 in the Supplementary Material). 
Taking into account the extracorporeal bypass volume of $30 \mathrm{~mL} \cdot \mathrm{kg}^{-1} \cdot \mathrm{min}^{-1}[7]$, we have scaled our oxygenator to a rated blood flow of $60 \mathrm{~mL} / \mathrm{min}$ which is an approximate minimum required for neonate applications. Thus, the gas exchange surface area and volume of the liquid chamber for the meander artificial lung with channels $100 \mu \mathrm{m}$ wide and membrane $100 \mu \mathrm{m}$ thick can theoretically approach to $0.25 \mathrm{~m}^{2}$ and $12.8 \mathrm{~mL}$, i.e. 600 modules arranged in parallel, to satisfy the oxygenation of a $2.0 \mathrm{~kg}$ infant. Matharoo et al [13] have recently described the in-vitro and in-vivo oxygenation performance of $\mu \mathrm{AL}$ based on stainless steel reinforced composite silicone membranes. Based on reported values in [13] using pure oxygen, the gas exchange surface area and priming volume for neonates scale to $0.04 \mathrm{~m}^{2}$ and $20 \mathrm{~mL}$ at the expense of a high pressure drop of 67 mbar. Finally, the predicted volume for the meander type microfluidic device is lower than the priming volume (arterial filter excluded) of commercial oxygenators for infants based on microporous hollow fibre membrane contactors, i.e. 38 and $81 \mathrm{~mL}$ respectively for QUADROX-i Neonatal and the QUADROX-i Pediatric respectively [28].

\section{Conclusions}

A simple, compact and easy to fabricate meander type microfluidic device with double side gas diffusion property and liquid channels $400 \mu \mathrm{m}$ wide and $100 \mu \mathrm{m}$ deep has been developed and successfully applied for oxygenation of sheep blood.

Computer simulations in COMSOL Multiphysics 5.0 have enabled the chip design to meet requirements for pressure drop and shear stress. In a step further, the oxygen transfer process has been mathematically described to predict the oxygenation performance of meander type microdevices. The reasonable agreement between the experimental results and the model predictions supports the model validation.

The blood was successfully oxygenated in the meander microdevice with $2.9 \mathrm{~cm}^{2}$ of gas exchange surface area up to approximately $93 \%-98 \%$ as a function of the blood flow rate ranging from 0.1 to $1 \mathrm{~mL} / \mathrm{min}$. The exhibited oxygen transfer rate values were in the range of previous publications, up to $92 \mathrm{~mL} / \mathrm{min} \cdot \mathrm{m}^{2}$ for $3.5 \mathrm{~L} / \mathrm{min} \cdot \mathrm{m}^{2}$ of blood flow rate.

Theoretical parametric analyses reveal that it is possible to increase the oxygen saturation level by $25 \%$ at a blood flow rate of $0.1 \mathrm{~mL} / \mathrm{min}$ and an average pressure drop of 22 mbar by reduction of both membrane thickness and channel width up to 100 $\mu \mathrm{m}$. Based on our microfabrication experience, the reduction of the membrane 
thickness and liquid channel width up to $100 \mu \mathrm{m}$ does not introduce any complexity to the easy to fabricate approach based on straightforward PDMS-casting \& release. Although membrane delamination and/or lateral deflection have to be considered upon realization and operation of devices with thinner (or taller) membranes; the integrity of the microfluidic chip can be guaranteed through careful engineering.

Thus, the predicted volume for the liquid chamber of the $\mu A L$ (excluding fluidic connections, transfer lines and flow distributors) to satisfy oxygenation of a $2.0 \mathrm{~kg}$ infant is $12.8 \mathrm{~mL}$. Such volume is lower in comparison to priming volume of commercial oxygenators for infants, and it is within the range of the predicted values for other microfluidic oxygenators scaled for rated blood flow [13].

Our future work [29], inspired from these encouraging results, is focused on the fabrication of three-dimensional $\mu A L s$ by $3 D$ printing technology for a more closely mimic their natural counterparts.

\section{Acknowledgements}

The authors would like to acknowledge the financial support from the Government of Aragon and the Education, Audiovisual and Culture Executive Agency (EU-EACEA) within the EUDIME - "Erasmus Mundus Doctorate in Membrane Engineering" program (FPA 2011-0014, SGA 2012-1719, http://eudime.unical.it). CIBERBBN is an initiative funded by the VI National R\&D\&i Plan 2008-2011 financed by the Instituto de Salud Carlos III with the assistance of the European Regional Development Fund. Authors acknowledge the LMA-INA for offering access to their instruments and expertise. 
Table 1

Table 1 Main parameters of the proposed meander vertical-type geometry chip

\begin{tabular}{cccccccc}
\hline $\begin{array}{c}\text { Memb } \\
\text { thick., } \mathrm{t}_{\mathrm{m}} \\
{[\mu \mathrm{m}]}\end{array}$ & $\begin{array}{c}\text { Memb } \\
\text { Area, SA } \\
{\left[\mathrm{cm}^{2}\right]}\end{array}$ & $\begin{array}{c}\text { Liq. } \\
\text { channel } \\
\text { width } \\
{[\mu \mathrm{m}]}\end{array}$ & $\begin{array}{c}\text { Gas } \\
\text { channel } \\
\text { width } \\
{[\mu \mathrm{m}]}\end{array}$ & $\begin{array}{c}\text { Meander } \\
\text { unit length } \\
{[\mathrm{mm}]}\end{array}$ & $\begin{array}{c}\text { Gas/liq } \\
\text { channel } \\
\text { depth } \\
{[\mu \mathrm{m}]}\end{array}$ & $\begin{array}{c}\text { Liq vol } \\
{[\mu \mathrm{L}]}\end{array}$ & $\begin{array}{c}\text { Chip } \\
\text { footprint } \\
{\left[\mathrm{cm}^{2}\right]}\end{array}$ \\
\hline 120 & 2.9 & 400 & 100 & 2 & 100 & 58 & 35.0
\end{tabular}

\# Membrane surface area for gas exchange calculated as explained in the Supplementary Material. 
Table 2

\begin{tabular}{|c|c|c|c|c|}
\hline Parameter & Symbol & Value & Units & Ref \\
\hline Solubility coefficient of $\mathrm{O}_{2}$ in plasma & $\alpha$ & $9.37 \cdot 10^{-4}$ & $\mathrm{~mol} \cdot \mathrm{m}^{-3} \cdot \mathrm{mbar}^{-1}$ & [20] \\
\hline Diffusion coefficient of $\mathrm{O}_{2}$ in plasma & $D_{b}$ & $1.8 \cdot 10^{-9}$ & $m^{2} \cdot s^{-1}$ & [20] \\
\hline Number of binding sites of $\mathrm{Hb}$ & $n$ & 2.85 & - & [17] \\
\hline $\begin{array}{l}\text { Partial pressure of } \mathrm{O}_{2} \text { at } 50 \% \text { blood } \\
\text { saturation* }\end{array}$ & $P_{50}$ & 38.7 & mbar & [17] \\
\hline $\mathrm{O}_{2}$ binding capacity of $\mathrm{Hb}$ & Hbs & $1.34 \cdot 10^{-6}$ & $m^{3} \cdot g^{-1}$ & \\
\hline $\mathrm{O}_{2}$ density & $d$ & 1331 & $g \cdot m^{-3}$ & \\
\hline Blood density & $\rho$ & 1050 & $\mathrm{~kg} \cdot \mathrm{m}^{-3}$ & [20] \\
\hline Blood viscosity & $\mu$ & $2.910^{-5}$ & mbar.s & [20] \\
\hline $\mathrm{O}_{2}$ permeability, PDMS & Perm & $1.12 \cdot 10^{-11 \#}$ & $\mathrm{~mol} \cdot \mathrm{m} \cdot \mathrm{m}^{-2} \cdot \mathrm{s}^{-1} \cdot \mathrm{mbar}$ & [26] \\
\hline
\end{tabular}

* at $37^{\circ} \mathrm{C}, \mathrm{pH} 7.4$ and $\mathrm{P}_{\mathrm{CO} 2}$ of 53.3 mbar; ${ }^{\#}$ equivalent to 334 Barrer 
Table 3

Table 3 Main blood parameters of each oxygenation experiment

Meander Design with vertical membrane device, MD

$[\mathrm{Hb}][\mathrm{g} / \mathrm{mL}] \quad \mathrm{S}_{02}$ inlet $[\%]$

Device 1

0.136

81.4

Device 2

0.145

83.7

Device 3

0.141

77.6 
Figure 1

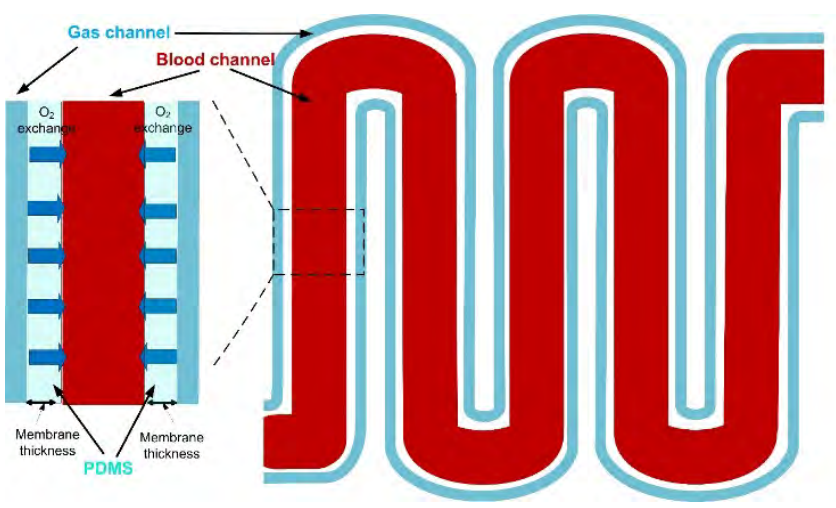

Figure 1. Schematic representation of the meandering channel arrangement, top view. 
Figure 2
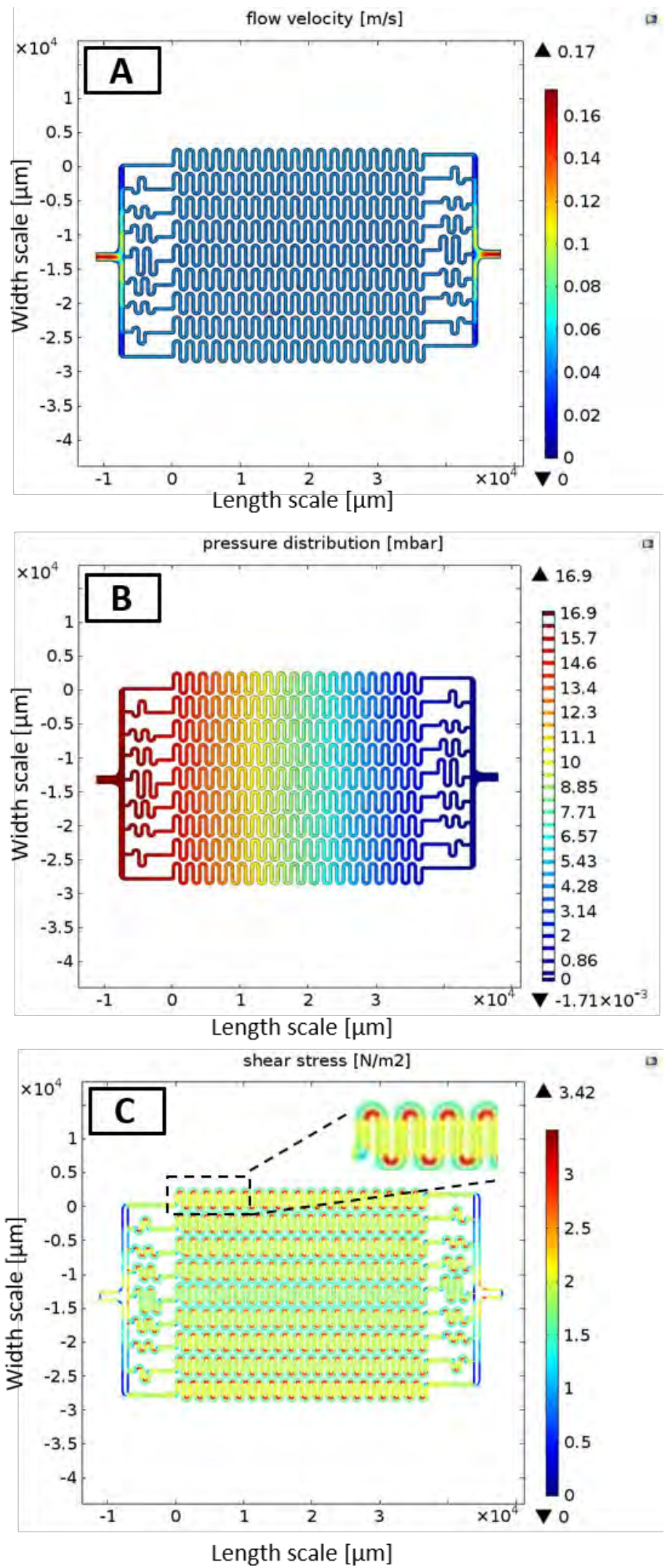

Figure 2. Computer modelling results of the meander design of A) liquid flow velocity, B) pressure distribution and C) shear stress for $1 \mathrm{~mL} / \mathrm{min}$ blood flow rate. (Grey-scale plotting as Figure $\mathrm{S} 2$ in Supplementary Material). 
Figure 3
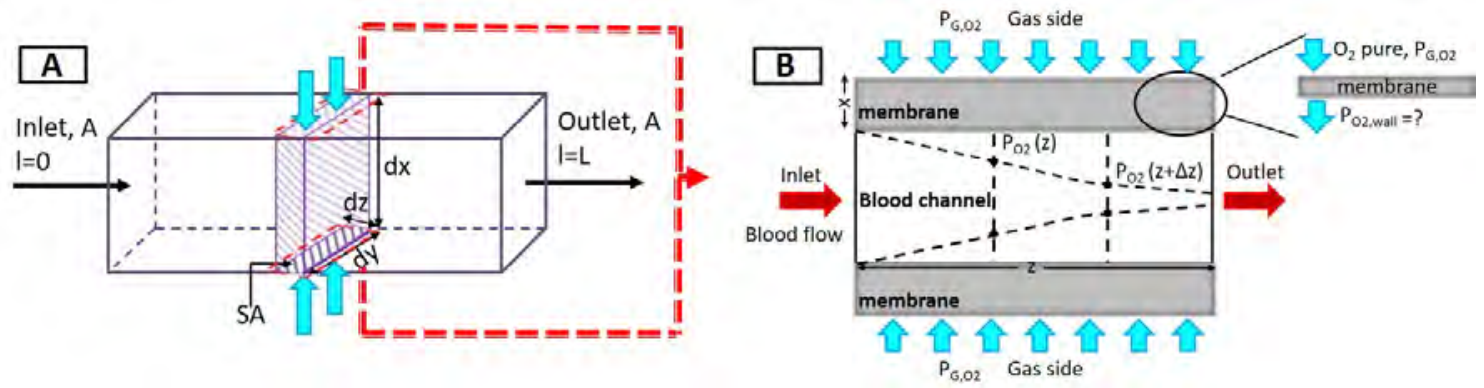

Figure 3. Schematic representation of the A) Cartesian control volume for the derivation of the species conservation equation, and B) boundary conditions in the double side oxygen diffusion system. 
Figure 4
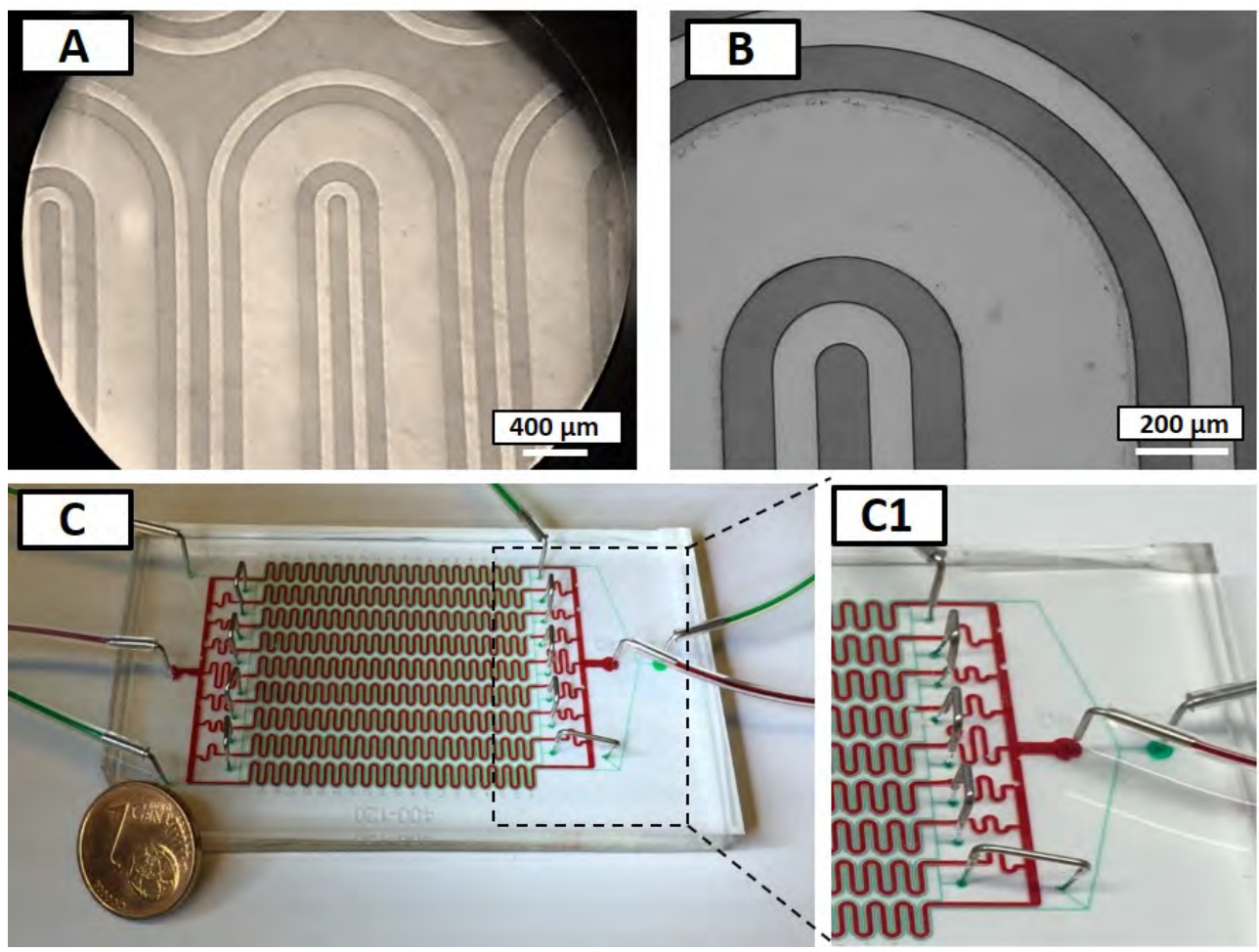

Figure 4. A) and B) SEM images; C) a photograph of a meandering design microfluidic chip and C1) magnification of the flow distributors and fluidic connections. Green and red colours indicate gas and liquid channels, respectively. 
Figure 5

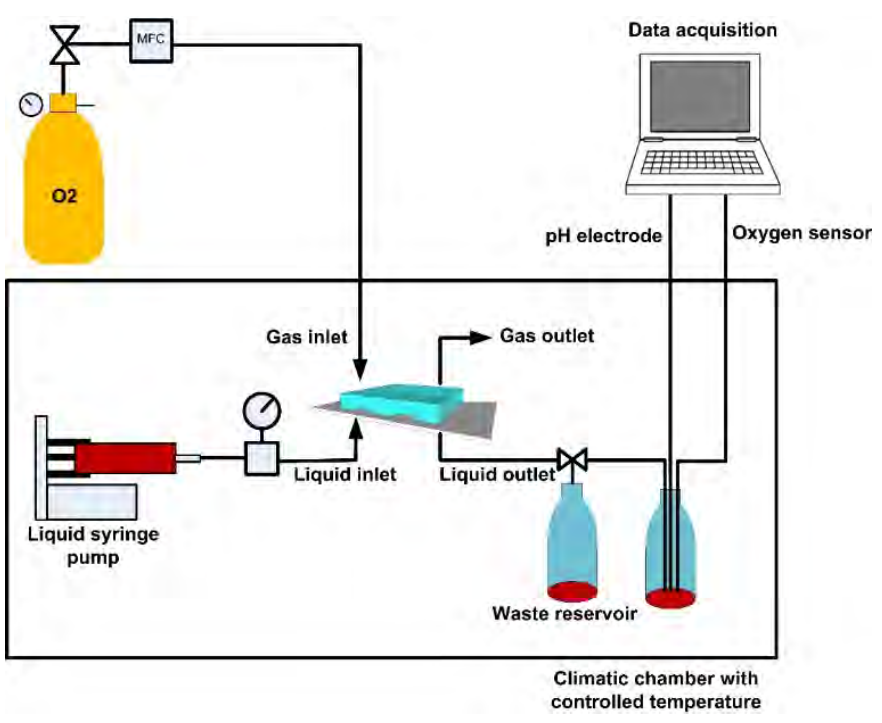

Figure 5. Experimental set-up for blood oxygenation experiments. 
Figure 6
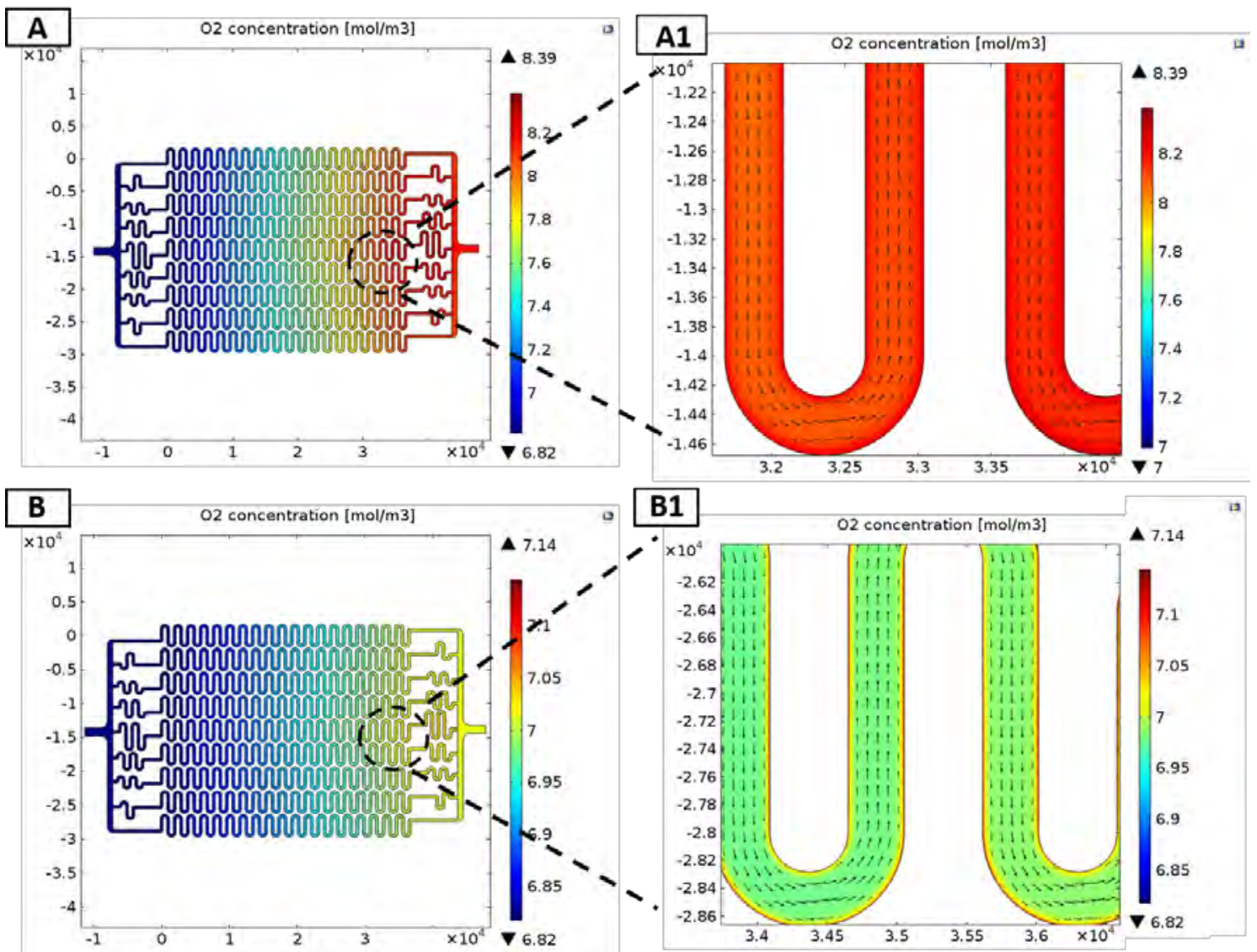

Figure 6. Numerical modelling results for the oxygen concentration profile in the meander device at A) $0.1 \mathrm{~mL} / \mathrm{min}$ blood flow rate and B) $1 \mathrm{~mL} / \mathrm{min}$ blood flow rate; and their respective magnifications showing the streamlines plot for the blood velocity. (Grey-scale plotting as Figure S3 in Supplementary Material). 
Figure 7

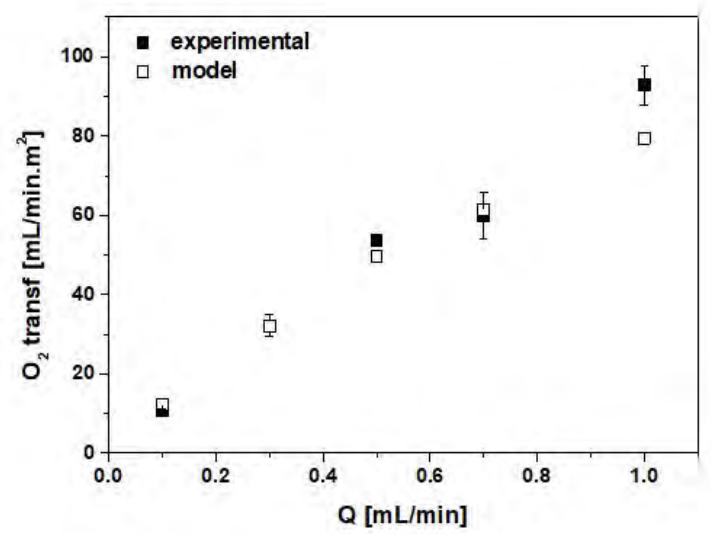

Figure 7. Comparison between the computationally modelled and experimentally obtained oxygen transfer rate values (average \pm SD) for the three identical devices (see Table 3 and Table S1) prepared for this work. 
Figure 8

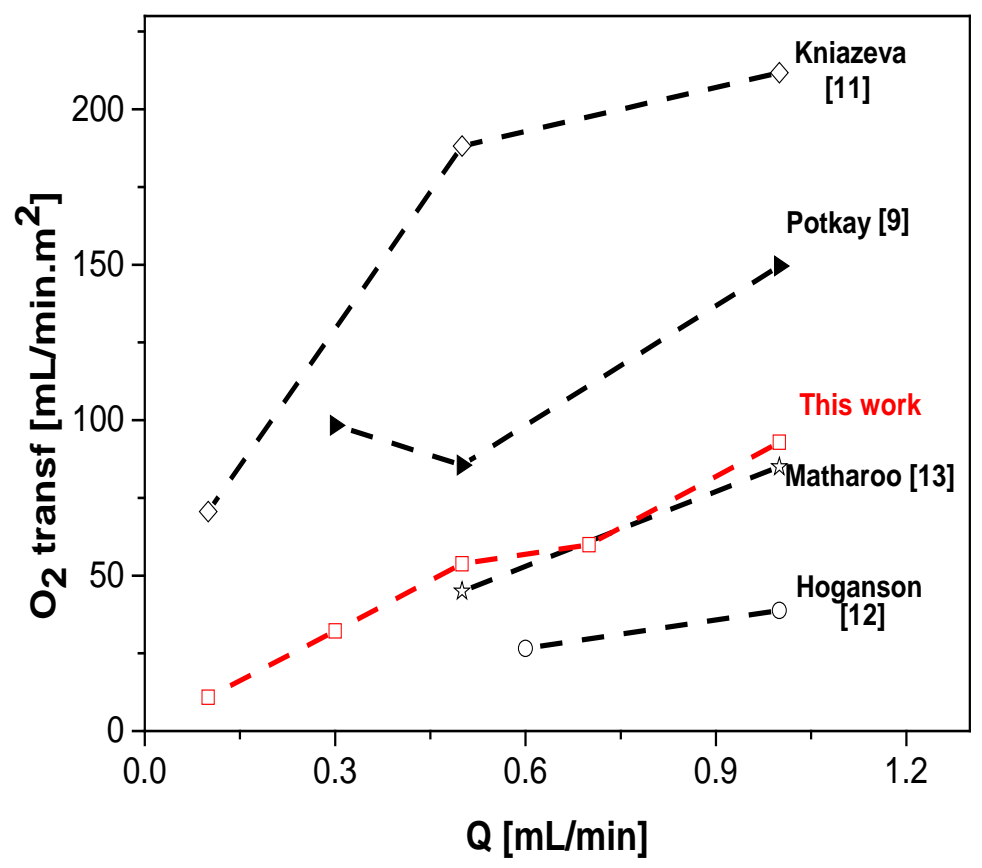

Figure 8. Oxygen transfer rate at various liquid flow rates for meander type device, $\mathrm{MD}$, in comparison to the leading groups at a blood flow in the range of $0.1-1 \mathrm{~mL} / \mathrm{min}$. Empty symbols indicate the experiments with pure oxygen as a gas phase, while filled symbols indicate the usage of air. 
Figure 9

\section{A}

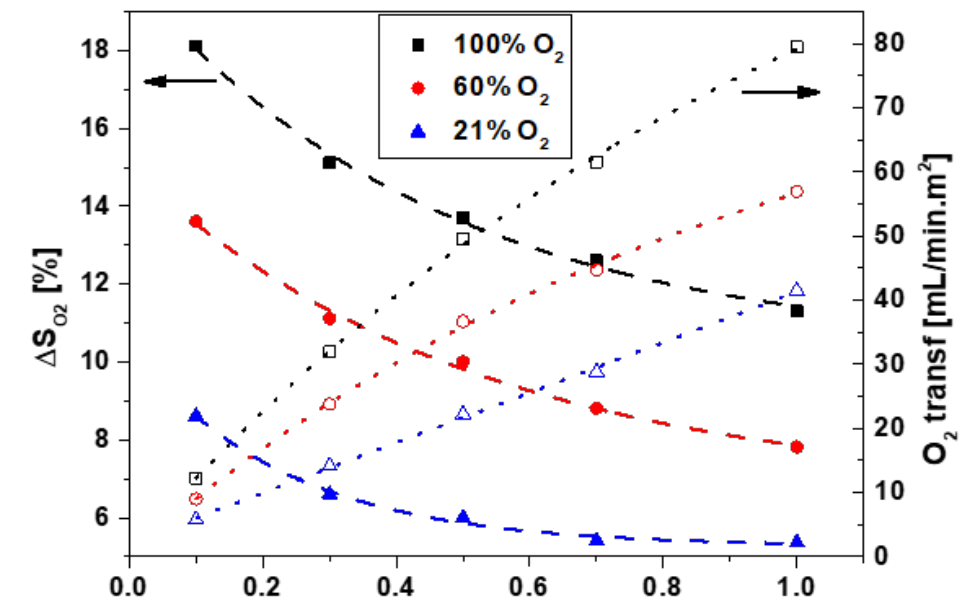

B $Q[\mathrm{~mL} / \mathrm{min}]$
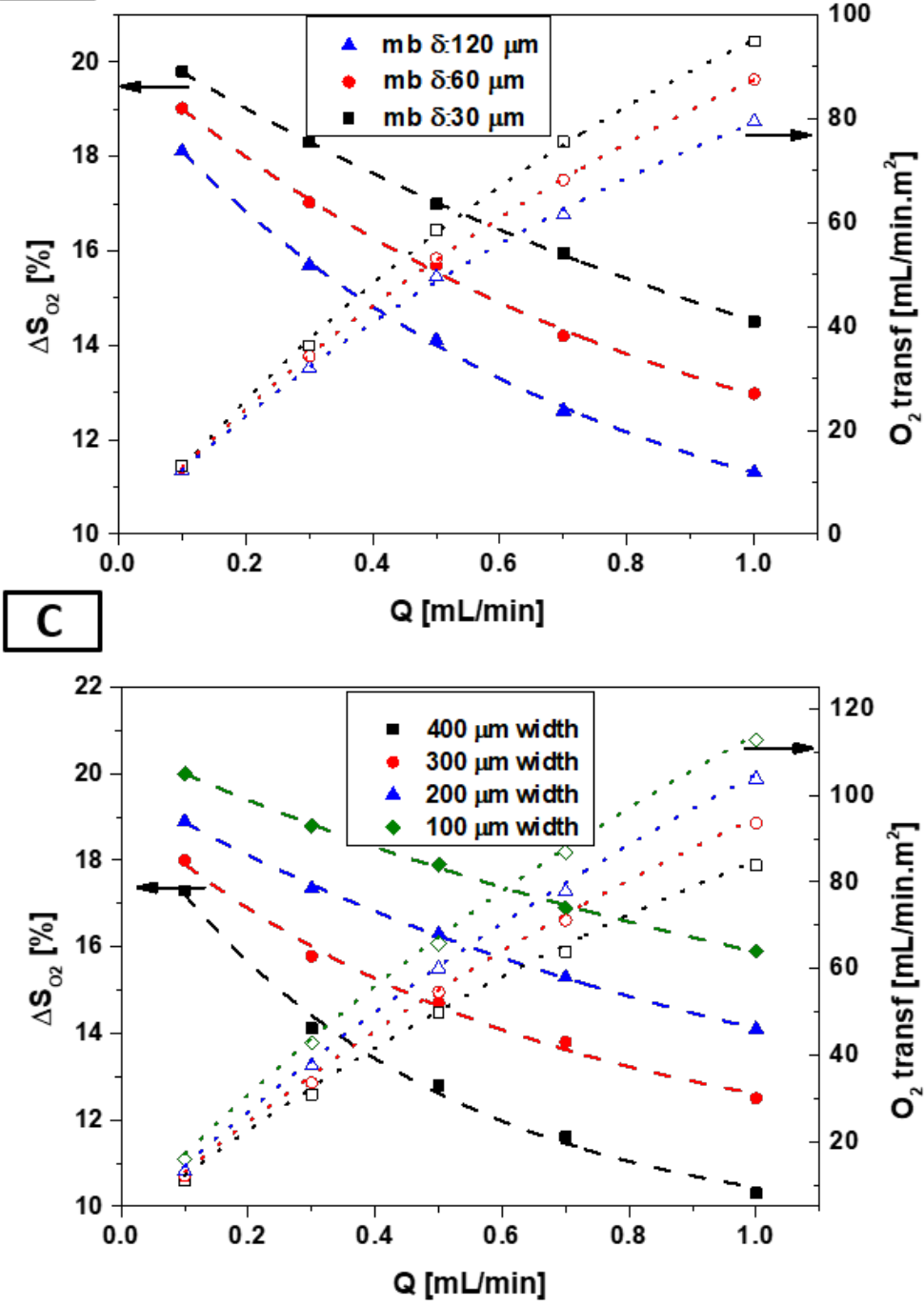

Figure 9. Influence of A) oxygen concentration in the source gas, B) membrane thickness and C) channel width in the meander device, on the oxygen transfer rate at different blood flow rates. Inlet saturation, $\mathrm{S}_{\mathrm{O} 2}=80 \%$, parameters for Hill equation see Table 2 . 
Figure 10

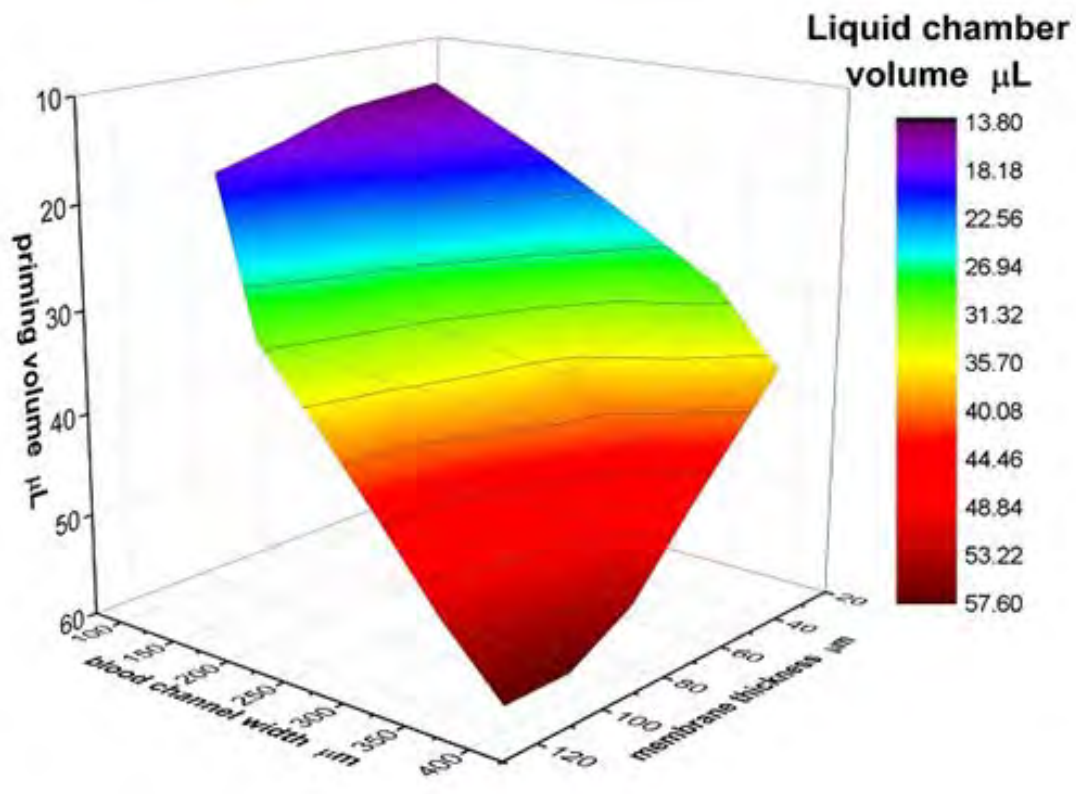

Figure 10. A theoretical plot demonstrating the impact of a microfluidic oxygenator device's membrane thickness and blood channel width on the liquid chamber volume. PDMS was assumed to be the membrane material and pure oxygen was supplied from the gas side. The blood flow rate is $0.1 \mathrm{~mL} / \mathrm{min}$ and the final $\mathrm{O}_{2}$ saturation at the outlet is assumed to be $95 \%$. 
[1] W.I. Wu, N. Rochow, E. Chan, G. Fusch, A. Manan, D. Nagpal, et al., Lung assist device: Development of microfluidic oxygenators for preterm infants with respiratory failure, Lab on a Chip - Miniaturisation for Chemistry and Biology, 13(2013) 2641-2650.

[2] D.M. Hoganson, J.L. Anderson, E.F. Weinberg, E.J. Swart, B.K. Orrick, J.T. Borenstein, et al., Branched vascular network architecture: A new approach to lung assist device technology, The Journal of Thoracic and Cardiovascular Surgery, 140(2010) 990-995.

[3] R. Sreenivasan, E.K. Bassett, D.M. Hoganson, J.P. Vacanti, K.K. Gleason, Ultra-thin, gas permeable free-standing and composite membranes for microfluidic lung assist devices, Biomaterials, 32(2011) 3883-3889.

[4] N. Rochow, A. Manan, W.I. Wu, G. Fusch, S. Monkman, J. Leung, et al., An integrated array of microfluidic oxygenators as a neonatal lung assist device: In vitro characterization and in vivo demonstration, Artificial Organs, 38(2014) 856-866.

[5] A.A. Gimbel, E. Flores, A. Koo, G. García-Cardeña, J.T. Borenstein, Development of a biomimetic microfluidic oxygen transfer device, Lab on a Chip, 16(2016) 3227-3324.

[6] A.J. Thompson, L.H. Marks, M.J. Goudie, A. Rojas-Pena, H. Handa, J.A. Potkay, A small-scale, rolled-membrane microfluidic artificial lung designed towards future large area manufacturing, Biomicrofluidics, 11(2017) 024113.

[7] J.A. Potkay, The promise of microfluidic artificial lungs, Lab on a Chip, 14(2014) 4122-38.

[8] A.J. Thompson, L.J. Ma, T.J. Plegue, J.A. Potkay, Design Analysis and Optimization of a Single Layer PDMS Microfluidic Artificial Lung, IEEE Transactions on Biomedical Engineering, doi: 10.1109/TBME.2018.2866782.

[9] J.A. Potkay, M. Magnetta, A. Vinson, B. Cmolik, Bio-inspired, efficient, artificial lung employing air as the ventilating gas, Lab on a Chip, 11(2011) 2901-2909.

[10] T. Kniazeva, J.C. Hsiao, J.L. Charest, J.T. Borenstein, A microfluidic respiratory assist device with high gas permeance for artificial lung applications, Biomedical Microdevices, 13(2011) 315-323.

[11] T. Kniazeva, A.A. Epshteyn, J.C. Hsiao, E.S. Kim, V.B. Kolachalama, J.L. Charest, et al., Performance and scaling effects in a multilayer microfluidic extracorporeal lung oxygenation device, Lab on a Chip - Miniaturisation for Chemistry and Biology, 12(2012) 1686-1695.

[12] D.M. Hoganson, H.I. Pryor Ii, E.K. Bassett, I.D. Spool, J.P. Vacanti, Lung assist device technology with physiologic blood flow developed on a tissue engineered scaffold platform, Lab on a Chip - Miniaturisation for Chemistry and Biology, 11(2011) 700-707.

[13] H. Matharoo, M. Dabaghi, N. Rochow, G. Fusch, N. Saraei, M. Tauhiduzzaman, et al., Steel reinforced composite silicone membranes and its integration to microfluidic oxygenators for high performance gas exchange, Biomicrofluidics, 12(2018) 014107.

[14] J.T. Borenstein, H. Terai, K.R. King, E.J. Weinberg, M.R. Kaazempur-Mofrad, J.P. Vacanti, Microfabrication technology for vascularized tissue engineering, Biomedical Microdevices, 4(2002) 167-175.

[15] M. Shin, K. Matsuda, O. Ishii, H. Terai, M. Kaazempur-Mofrad, J. Borenstein, et al., Endothelialized networks with a vascular geometry in microfabricated poly(dimethyl siloxane), Biomedical Microdevices, 6(2004) 269-278.

[16] L.F.Mockros, K.E.Cook, Engineering design of thoracic artificial lungs. The Artificial Lung, Austin, TX, Landes Biosciences Publishers, 2002, 33-64.

[17] L.F. Mockros, R. Leonard, Compact cross-flow tubular oxygenators, Transactions American Society for Artificial Internal Organs, 31(1985) 628-633.

[18] T. Rieper, C. Müller, H. Reinecke, Novel scalable and monolithically integrated extracorporeal gas exchange device, Biomedical Microdevices, 17(2015) 86.

[19] J.A. Potkay, A simple, closed-form, mathematical model for gas exchange in microchannel artificial lungs, Biomedical Microdevices, 15 (2013) 397-406. 
[20] J. Zhang, T.D.C. Nolan, T. Zhang, B.P. Griffith, Z.J. Wu, Characterization of membrane blood oxygenation devices using computational fluid dynamics, Journal of Membrane Science, 288(2007) 268-279.

[21] S. McKee, E.A. Dougall, N.J. Mottram, Analytic solutions of a simple advection-diffusion model of an oxygen transfer device, Journal of Mathematics in Industry, 6(2016) 3.

[22] T.C. Merkel, V.I. Bondar, K. Nagai, B.D. Freeman, I. Pinnau, Gas sorption, diffusion, and permeation in poly(dimethylsiloxane), Journal of Polymer Science: Part B: Polymer Physics, 38 (2000) 415-434 .

[23] B.G. Subramani, P.R. Selvaganapathy, Surface micromachined PDMS microfluidic devices fabricated using a sacrificial photoresist, Journal of Micromechanics and Microengineering, 19(2009) 015013.

[24] N. Rochow, E.C. Chan, W.I. Wu, P.R. Selvaganapathy, G. Fusch, L. Berry, et al., Artificial placenta - Lung assist devices for term and preterm newborns with respiratory failure, International Journal of Artificial Organs, 36(2013) 377-391.

[25] S. Bhattacharya, A. Datta, J.M. Berg, S. Gangopadhyay, Studies on surface wettability of poly (dimethyl) siloxane (PDMS) and glass under oxygen-plasma treatment and correlation with bond strength, Journal of Microelectromechanical Systems, 14(3)(2005) 590-597.

[26] K.S. Houston, D.H. Weinkauf, F.F. Stewart, Gas transport characteristics of plasma treated poly(dimethylsiloxane) and polyphosphazene membrane materials, Journal of Membrane Science, 205(2002) 103-112.

[27] E. Davydova, S. Wouters, S. Deridder, G. Desmet, S. Eeltink, P.J. Schoenmakers, Design and evaluation of microfluidic devices for two-dimensional spatial separations, Journal of Chromatography A, 1434 (2016) 127-35.

[28] Safe, high-performance oxygenators for the smallest patients, available from:https://www.getinge.com/int/product-catalog/quadrox-i-neonatal-and-pediatric/.

(Accessed on December 18).

[29] E. Lamperti, R. Manno, M. Urbiztondo, M. Malankowska, M.P. Pina, R. Mallada, 3D PDMS microfluidic membrane contactors for $\mathrm{CO}_{2}$ separation. Book of Abstracts, Euromembrane 2018, Valencia (Spain). 